\title{
Impact of internal migration on political participation in Turkey
}

\author{
Ali T Akarca ${ }^{1 *}$ and Aysit Tansel 2,3,4
}

\footnotetext{
* Correspondence: akarca@uic.edu 'Department of Economics (mc 144), University of Illinois at Chicago, $601 \mathrm{~S}$. Morgan Street, Chicago, Illinois 60607, USA

Full list of author information is available at the end of the article
}

\begin{abstract}
The Impact of population mobility on provincial turnout rates in the 2011 Turkish parliamentary election is studied, controlling for the effects of other socio-economic, demographic, political and institutional factors. Consequences of migration both at destinations and origins are considered. According to the robust regressions estimated, the relationship between turnout and education is inverse U-shaped, and between turnout and age (including generational effects), it is U-shaped. Immigration, emigration, large population, a large number of parliament members elected from a constituency, participation by large number of parties, and existence of a dominant party depress the turnout rate. However, at destinations where large numbers of immigrants from different regions are concentrated, the opportunity afforded to them to elect one of their own reduces the adverse impact of immigration significantly and in some cases even turns it to positive. That emigration, and education beyond certain level, have negative effects on turnout, that immigration's adverse effect is less in areas with high migrant concentrations, and that in Turkey, political participation is highest among the youngest voters are the novel findings of the study. The latter finding may explain why voter turnout declines in Europe and North America but not in Turkey.
\end{abstract}

JEL Classifications: D72; J61

Keywords: Election; Turnout; Voter behavior; Political participation; Internal migration; Turkey

\section{Introduction}

During the last sixty years, about 7 to 8 percent of the Turkish population has moved from one province to another in every five-year interval. As can be observed from Figures 1 and 2, this movement was essentially from the east and north towards the west and south, that is, from the less developed and poorer parts of the country to the more industrialized and richer regions. As a consequence of this massive internal migration, the urbanization rate has increased from about 25 percent in 1950 to 42 percent in 1975, 65 percent in 2000, and 77 percent in 2011. Now 39 percent of Turkish population resides in a province other than the one in which they were born. This figure was 28 percent in 2000, 17 percent in 1975, and only 12 percent in $1950^{1}$. Six provinces which collectively make up a third of the country's resident population have more immigrants than people born there. Only 16 percent of residents in Istanbul province, which includes Turkey's largest metropolis, and only 32 percent of those in Ankara province, which includes country's capital and its second largest city, were born 


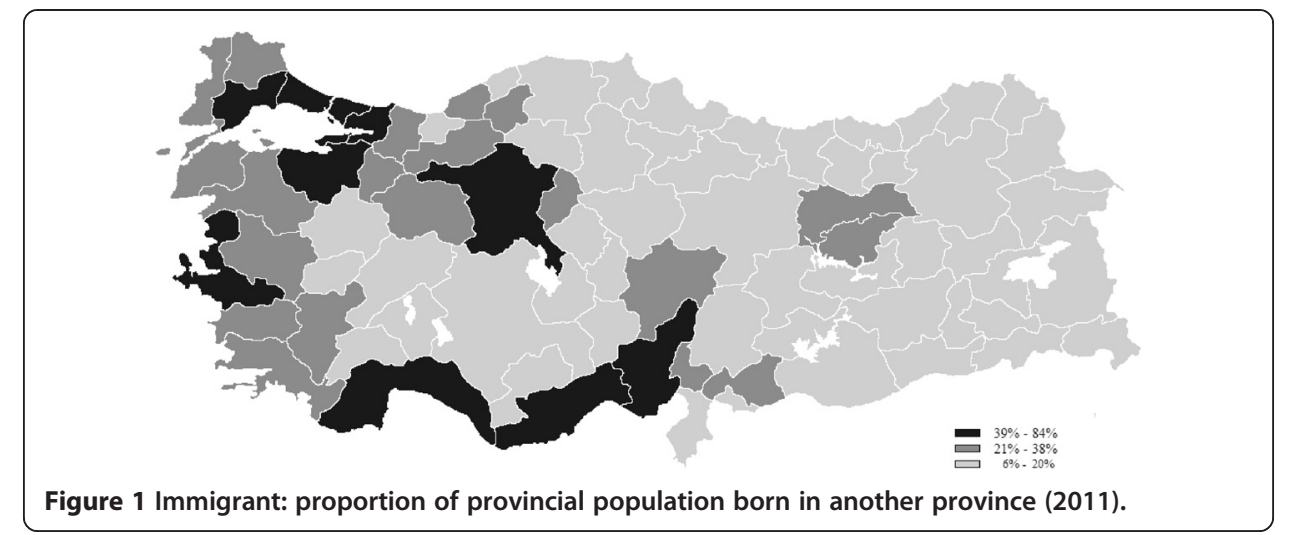

there. On the other hand, more than half of the people born in thirty-four of the eighty-one provinces were living elsewhere. Less than a fifth of those born in Ardahan and only about a quarter of those born in Çankırı, Tunceli, and Bayburt reside in their birth provinces.

The main purpose of this study is to investigate the impact of such large population movements on political participation in Turkey. We examine the impact on the voter turnout not only at the destinations of migrants but also at locations they have left. The former is studied extensively in the literature, but political consequences of migration for sending communities are highly neglected. The small number of studies that exist limited their analysis to a few specific cases and to the effects of remittances and brain drain in the context of international migration, not internal. This is one of the gaps in the migration and turnout literatures we hope to fill.

To measure the effects of immigration and emigration on turnout properly, naturally we will have to control for and estimate the impacts of other socio-economic, demographic, political and institutional factors as well. Producing this information is another purpose of this study. There are only three studies on voter turnout in Turkey that go beyond an analysis of descriptive statistics or pairwise simple correlations: a micro study by Cesur and Mocan (2013) and macro studies by Başlevent (2013) and Çulhaoğlu (2007). These studies consider socio-economic factors, but none of them take emigration into account. While the first two include immigration in their regressions, they ignore

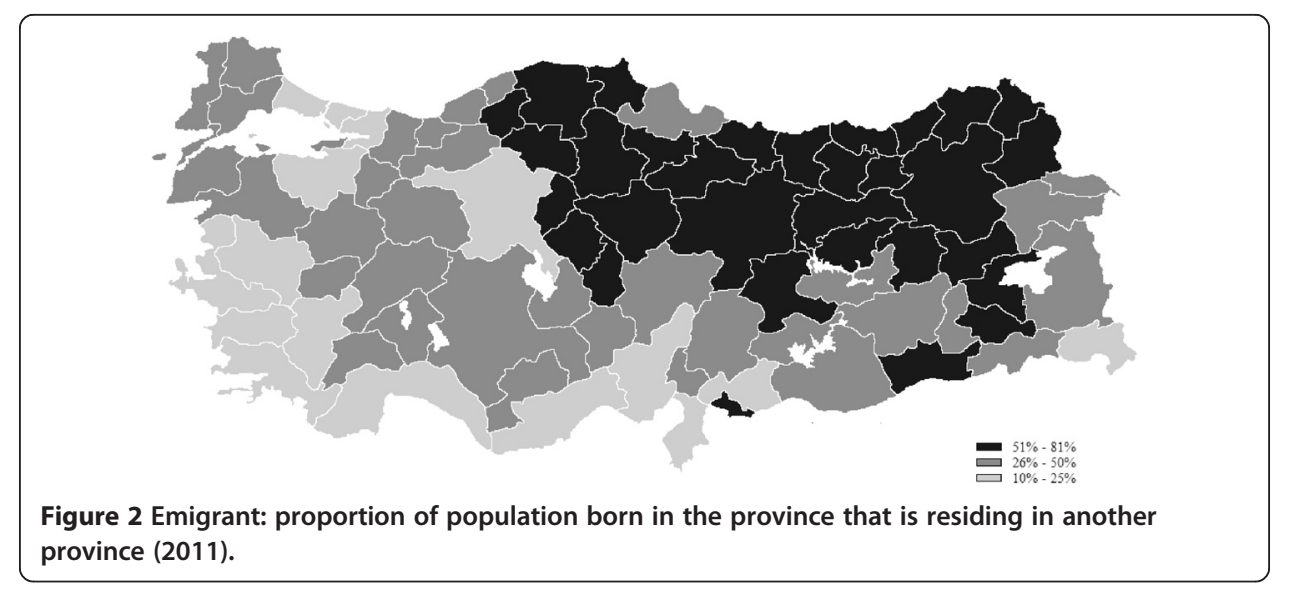


political and institutional factors. The last one, on the other hand, includes political and institutional variables, but none on immigration. By including all types of variables mentioned in our turnout equation, we hope to measure their individual effects more accurately.

Our study should be of interest not only for those specializing in Turkey but for those studying the impact of immigration and emigration in other countries as well. Our results may be of value in particular to those investigating determinants of political participation in West Europe and North America. Most of the countries in the latter two regions are experiencing steady declines in voter turnout, which have reached alarming levels ${ }^{2}$. No such tendency exists in Turkey, where the turnout rate is about twice as high as in many industrialized nations. Capturing some of the factors which make the Turkish rate so high and non-declining can shed light on the situation in Western countries.

The paper is organized as follows. In the next section, determinants of voter turnout are discussed, and a model is specified for the Turkish 2011 parliamentary election. In section 3, empirical results are presented, interpreted, and compared to those obtained by other studies. Finally in section 4 , the conclusions reached are summarized.

\section{Turnout and its determinants}

Studies on turnout define their dependent variable as the ratio of the number of voters to one of the following: the entire population, the voting-age population, the eligible population, or the number of registered voters. Although the first two are considered often due to the ease with which they can be obtained, obviously the latter two are more proper and will be our choice. These are identical in our case due to the switch in Turkey in 2008 to a system of automatic registration of all citizens eligible to vote without any effort on their part $^{3}$.

According to Geys (2006), who surveyed 83 aggregate-level studies, in explaining turnout, researchers typically consider socio-economic and demographic variables such as population's size, density, stability, homogeneity, and the turnout rate in the previous election, political variables such as effective number of parties and the level of electoral competition, and institutional variables such as the election system, registration and voting requirements, and the presence of other elections on the ballot. He notes that among these variables, those on population size, population mobility and political competition appear to be most important, and those on population concentration and homogeneity are not important at all. The findings on variables relating to political fragmentation on the other hand are ambiguous. Although some studies also consider the age and education structures of the population, Geys disregards them on the grounds that interpretations of their parameters carry a potential danger for ecological fallacy. However, Smets and Van Ham (2013), who surveyed 90 individual-level studies, note that education and age are the two most common independent variables in such studies, and the two that are found to be most successful. We believe that as long as one is cautious about deducing individual level relationships from patterns observed in aggregate-level data, controlling for age and education would be beneficial rather than harmful.

For brevity, we will not review all of the papers published since the Geys (2006) survey. These studies considered variables similar to the ones used by earlier studies, as we will 
do here. However, we will ignore institutional variables relating to election system and type, day of the week and month of the year the election is held, time elapsed since the last election, voting age, whether voting is compulsory or optional, and the ease of registration, as these do not vary in our data. The 2011 election is held on the same day and under the same rules in every province.

The main determinants we consider are the following:

PRIMARY: Percentage of provincial population with at least primary school (5 years of) education.

HIGHER: Percentage of provincial population with at least university education.

UNDER30: Percentage of provincial population between the ages of 20 and $29^{4}$.

OVER60: Percentage of provincial population over age 60.

URBAN: Percentage of provincial population living in provincial and district capitals.

MP: Number of parliament members elected by the constituency ${ }^{5}$.

PARTIES: 10,000 divided by the sum of squared vote shares of the AKP, CHP, MHP and $\mathrm{BDP}^{6}$.

NOCOMPETITION: A dummy variable which takes the value of 1 if all parliamentary seats of a province are won by one party, and zero otherwise ${ }^{7}$

EMIGRANT: Percentage of those born in the province living in another province.

IMMIGRANT: Percentage of provincial population born in another province.

MP $\times$ IMMIGRANT/100: Product of MP and IMMIGRANT, divided by 100 .

The first eight of the above variables are included in our model to control for socioeconomic, demographic, political and institutional characteristics of provinces so that we can estimate the parameters of the last three variables more accurately. Although the results pertaining to the first group of variables are important in their own right, here our main focus will be on the impact of the last three, dealing with migration.

The motivation for considering PRIMARY is that without some minimum level of education, the act of voting alone could be a difficult task, let alone gathering and evaluating information on candidates, parties and issues facing the country and the province. We presume that for most people, primary school education can be taken as that critical level. Although one's faculty for gathering information and voting rises with increased education, it is likely to be subject to diminishing returns. Furthermore, the opportunity cost of one's time rises as his/her education rises, especially after graduation from university. The HIGHER variable is added to see if the effect of education on turnout dampens when the province has more people with higher education.

As one ages, one accumulates resources, becomes more experienced, more informed, more settled, and acquires a greater sense of responsibility. These will increase the probability that he/she will vote. On the other hand, the opportunity cost of time increases and health deteriorates as one gets older, which creates disincentives to vote. Consequently, the age-turnout relation is likely to be curvilinear. For that reason, modelers often include in their turnout equations, in addition to age, age-squared.

Individuals born and raised in the same time period are exposed to the same socio-historical events which shape their political socialization. Consequently, political participation may vary between generations too. Bhatti and Hansen (2012) argue that this may be the reason behind the curvilinear relationship observed between age and turnout. 
For instance, the old may turnout in larger numbers than young individuals not due to age per se, but simply because they belong to a generation with higher turnout levels. It is not possible to separate the age and generation effects from each other in aggregate-level studies examining a single election, such as ours. We have included in our equation UNDER30 and OVER60 variables to measure the combined effects of age and generation.

Individual-level studies find that participation in elections is much higher in rural areas than in urban areas. Voting in urban areas is more cumbersome and the stigma associated with not voting is less as it will be hardly noticed in the anonymity of the city. Villages on the other hand are closely knit societies where each person has intimate knowledge about the activities of others. To capture this, the URBAN variable is considered. However, in Turkey, the urbanization rate is not defined as the proportion of the provincial population living in cities over a certain size but as the proportion residing in provincial and district capitals. As many district capitals are really small towns, only slightly larger than large villages, this definition does not fully reflect the urbanization level of a province. As highly urbanized provinces have large number of parliament members, the MP variable probably captures the urbanization level better. With the MP variable in the equation, the coefficient of URBAN can be interpreted as how the turnout differs between truly urban areas and typical district and provincial capitals. There are other reasons for utilizing MP. It reflects also the population size of the constituency, the complexity of the ballot, and the cost involved in gathering information about the candidates.

A larger effective number of parties (PARTIES) raise the probability that voters can find a party with which they identify, encouraging participation. On the other hand, it also makes it harder for the voters to make up their minds. Also, in a proportional election system, if the share of the top party is relatively high, dispersion of the rest of the votes among many other parties may reduce competition by letting the top party capture a disproportionate number of the seats. The last two reasons may discourage the voters to turn out. Thus, the impact of political fragmentation on turnout is ambiguous.

In parliamentary elections, competition is nationwide. Even when an election in a province is very lop-sided, as long as a voter has a chance to affect the allocation of a seat, he/she will have an incentive to cast a ballot. When a dominant party sweeps all of the seats in a constituency, that chance is extinguished. NOCOMPETITION variable is considered to measure the effect of such an occurrence ${ }^{8}$.

We now turn to our variables of main interest, EMIGRANT and IMMIGRANT. The coefficient of the former measures the impact of migration at the origin and the latter at the destination. We expect both variables in question to be inversely related to the turnout. There are at least three reasons for this in the case of EMIGRANT. First, people who emigrate are likely to be the ones who are most active politically. Second, remittances sent by these people to their relatives back home reduce the latter's dependence on the state and thus decrease their incentives to get involved with politics. Third, the ones left behind may be just waiting for their turn to migrate and thus lose interest in local affairs. In the case of IMMIGRANT, if voting is habit-forming as some studies on other countries show, and if the political behavior of the migrants is similar to the behavior of the people in their origin areas - as Pikkov (2011), Akarca and Başlevent (2010) and Akarca and Tansel (2007) show-then we would expect a smaller portion of immigrants to cast a ballot compared to the native born population. As explained above, 
migrant producing provinces have low turnout rates. Also, provinces with immigrants from all over the country have less sense of community. Furthermore, immigrants are too busy trying to make it in the big city to spare time for political activity. They have less knowledge of candidates and issues at their new locations, and those issues may not be their own. Consequently fewer of them vote. However, an exception has to be made in the case of large urban constituencies where high numbers of immigrants from particular regions of the country are concentrated and where the number of deputies being elected is large. In such provinces, seeing an opportunity to elect one of their own, immigrants will have higher incentives to participate. The interaction term of MP and IMMIGRANT is introduced to capture this.

It will be useful to also consider two other versions of the main model, one which adds the turnout rate in the previous parliamentary election (TURNOUT20007) and another which adds regional dummy variables. Many studies indicate that voting is habit-forming. People who voted in the past are more likely to turnout in future elections. The first extension would take this into account. However, there is a drawback to including a lagged dependent variable in the model. The previous turnout is likely to be effected by the very same variables that current turnout is, as socio-economic, demographic, political and institutional variables change very gradually over time. Thus, at least to some extent, this variable would capture the effects of other independent variables besides habit formation. Consequently it is wise to estimate the model with and without this variable. The second extension would enable us to check if variables included in the model adequately represent regional differences in Turkey and to capture them if they do not. For this purpose, we partitioned the country into four regions (WEST, NORTH, CENTRAL and EAST), shown in Figure 3, based on a finer breakdown by Turkstat ${ }^{9}$.

\section{Empirical results}

Summary statistics on variables mentioned in the previous section and sources of data on them are presented in Table 1. The estimates of the three equations discussed above are given in Tables 2 and 3. Because initial estimations performed using the Ordinary Least Squares method indicated the presence of a number of outliers and near outliers, estimation is subsequently done utilizing a robust regression method instead. Two different types of robust regression procedures are utilized. Table 2 presents robust regression coefficients obtained through the

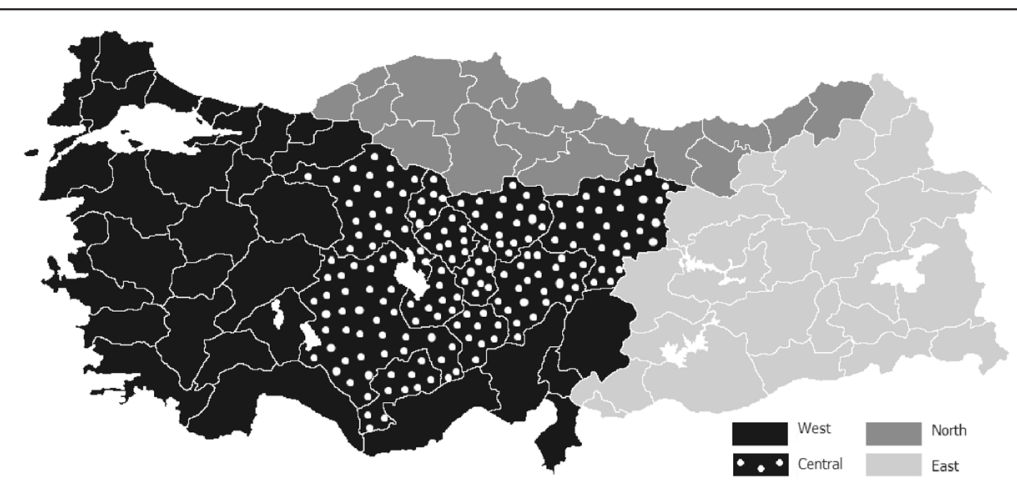

Figure 3 Four-way partition of Turkey based on TurkStat's 12-region classification. 
Table 1 Descriptive Statistics

\begin{tabular}{lrccc}
\hline Independent variables & Mean & Standard deviation & Minimum & Maximum \\
\hline PRIMARY & 72.01 & 9.83 & 46.44 & 85.00 \\
HIGHER & 7.78 & 2.47 & 3.49 & 16.84 \\
UNDER30 & 16.63 & 2.20 & 13.71 & 28.20 \\
OVER60 & 12.29 & 4.12 & 4.01 & 21.76 \\
URBAN & 64.51 & 13.63 & 34.83 & 98.96 \\
MP & 5.74 & 4.55 & 1.00 & 28.30 \\
PARTIES & 2.33 & 0.41 & 1.45 & 3.50 \\
NOCOMPETITION & 0.17 & 0.38 & 0.00 & 1.00 \\
EMIGRANT & 43.12 & 18.34 & 10.23 & 80.82 \\
IMMIGRANT & 21.33 & 15.56 & 5.81 & 83.92 \\
(MPXIMMIGRANT)/100 & 1.65 & 3.18 & 0.16 & 23.75 \\
TURNOUT2007 & 84.20 & 4.74 & 71.03 & 92.75 \\
TURNOUT2011 & 86.66 & 3.58 & 74.76 & 92.00 \\
WEST & 0.37 & 0.49 & 0.00 & 1.00 \\
NORTH & 0.20 & 0.40 & 0.00 & 1.00 \\
CENTRAL & 0.14 & 0.34 & 0.00 & 1.00 \\
\hline
\end{tabular}

Note: For all variables, except TURNOUT2007, their 2011 values are used.

Sources: Tuncer (2011) for MP, PARTIES, NOCOMPETITION, and TURNOUT2011; Tuncer (2007) for TURNOUT2007; Turkstat for all other variables.

M method introduced by Huber (1973). The chi-square statistics used to test the significance of parameters, probability values of which are given in the table, makes use of robust standard errors produced by the procedure. M-estimation performs well when the problems with outliers are in the Y-direction (response direction) but might yield improper results if the data are contaminated in the X-space (that is, in the covariate space). The LTS (the least trimmed squares) method is introduced by Rousseeuw (1984) and developed further by Rousseeuw and Van Driessen (2000) and Zaman et al. (2001) to deal with the latter case. This method first detects outliers and deletes them from the data. Then it obtains parameter estimates by minimizing the sum of remaining (trimmed) squares of residuals. Table 3 presents the results obtained through the LTS method.

The parameter estimates given in Tables 2 and 3 are quite similar. The numbers in parentheses next to the estimates are the probability values relevant to the chi-square test of whether the associated coefficient is equal to zero. According to the results presented in the first columns of these tables, each percentage increase in the portion of the population with at least five years of formal education increases turnout rate by 0.23 percentage points. This becomes about -0.12 for university graduates. Başlevent (2013), who studied the 2011 Turkish parliamentary election at the provincial level, also finds an inverse U-shaped relationship between mean years of schooling and the turnout rate. Although most studies find that turnout increases as the proportion of those with some basic level of education (for example primary school or high school education) increases, we are not aware of other papers which find a negative effect of education beyond some level of education. There are studies however which show that the positive impact of education turns to zero, if not negative, after a certain level of schooling. Cebula and Toma (2006) find that when the proportion of college graduates in a U.S. state is added as an independent variable in a turnout regression, which already includes the proportion 
Table 2 Estimated robust regressions (Method: $M$ )

\begin{tabular}{lrrr}
\hline Independent variables & Regression 1 & Regression 2 & Regression 3 \\
\hline CONSTANT & $67.359(0.00)$ & $50.638(0.00)$ & $67.781(0.00)$ \\
PRIMARY & $0.227(0.00)$ & $0.128(0.00)$ & $0.214(0.00)$ \\
HIGHER & $-0.340(0.04)$ & $-0.265(0.03)$ & $-0.319(0.08)$ \\
UNDER30 & $0.512(0.00)$ & $0.092(0.29)$ & $0.519(0.00)$ \\
OVER60 & $0.323(0.03)$ & $0.071(0.39)$ & $0.330(0.01)$ \\
URBAN & $0.049(0.04)$ & $0.043(0.01)$ & $0.048(0.05)$ \\
MP & $-0.344(0.01)$ & $-0.230(0.02)$ & $-0.342(0.01)$ \\
PARTIES & $-0.698(0.23)$ & $-0.664(0.13)$ & $-0.725(0.25)$ \\
NOCOMPETITION & $-0.686(0.30)$ & $-0.438(0.38)$ & $-0.700(0.34)$ \\
EMIGRANT & $-0.113(0.00)$ & $-0.058(0.00)$ & $-0.110(0.00)$ \\
IMMIGRANT & $-0.072(0.05)$ & $-0.036(0.18)$ & $-0.071(0.06)$ \\
(MPXIMMIGRANT)/100 & $0.339(0.09)$ & $0.248(0.10)$ & $0.335(0.11)$ \\
TURNOUT 2007 & & $0.354(0.00)$ & \\
WEST & & & $0.262(0.82)$ \\
NORTH & & & $0.079(0.94)$ \\
CENTRAL & 0.55 & 0.63 & $0.319(0.74)$ \\
R-SQUARE & & & 0.55 \\
\hline N & & &
\end{tabular}

Notes: The dependent variable is the turnout rate in the 2011 parliamentary election. Definitions of independent variables are given in section 2. Estimates are obtained using the ROBUSTREG procedure of the SAS statistical package with Method $=\mathrm{M}$ option. The numbers in parantheses next to the parameter estimates are the probabilities relevant to the chi-square test of whether the associated coefficient is equal to zero.

of high school graduates, it fails to make a significant contribution to the explanation. Berinsky and Lenz (2011) show that an increase in college enrollment of male students, resulting from an effort to avoid the draft during the Vietnam War, did not cause a rise in the turnout rate later. Taking advantage of another natural experiment, Cesur and Mocan (2013) find that raising compulsory schooling from 5 to 8 years in Turkey in 1997 did not result in a rise in the turnout rate in 2011 parliamentary election ${ }^{10}$. This result justifies also our choice of primary education as the benchmark in our turnout equation.

As we mentioned above, the age-related parameters in Table 2 should be viewed as the net result of age and generation effects. These indicate that a province's turnout rate rises as the proportions of voters over 60 and under 30 in that province rise relative to those in their middle ages. A percentage point rise in these raises the turnout rate $0.46-0.51$ and 0.32 points, respectively. This result is consistent with the U-shaped relationship found between provincial mean age and turnout in Turkey by Başlevent (2013). It is also consistent with the generational patterns observed in European and North American countries. Analyzing European data, Bhati and Hansen (2012), Gallego (2009) and Wass (2007), analyzing Costa-Rican data, Remmer (2010), analyzing U.S. data, Cebula and Toma (2006), and analyzing Canadian data, Blais et al. (2004) find that political participation among baby boomers and the generation preceding it to be substantially higher than the generations which followed them. It appears that the same is true for the Turkish case. However, our results suggest that the turnout rate which declined in the post baby-boomer generations has more than recovered in Turkey among people born after 1980, contrary to what is found for Western countries by the studies mentioned. 
Table 3 Estimated robust regressions (Method: LTS)

\begin{tabular}{lrrr}
\hline Independent variables & Regression 1 & Regression 2 & Regression 3 \\
\hline CONSTANT & $68.424(0.00)$ & $51.516(0.00)$ & $68.717(0.00)$ \\
PRIMARY & $0.227(0.00)$ & $0.128(0.00)$ & $0.210(0.00)$ \\
HIGHER & $-0.355(0.02)$ & $-0.222(0.07)$ & $-0.342(0.03)$ \\
UNDER30 & $0.456(0.03)$ & $0.046(0.58)$ & $0.487(0.00)$ \\
OVER60 & $0.325(0.00)$ & $0.061(0.44)$ & $0.325(0.01)$ \\
URBAN & $0.052(0.01)$ & $0.038(0.02)$ & $0.049(0.02)$ \\
MP & $-0.358(0.00)$ & $-0.204(0.04)$ & $-0.359(0.00)$ \\
PARTIES & $-0.766(0.16)$ & $-0.619(0.15)$ & $-0.794(0.18)$ \\
NOCOMPETITION & $-0.682(0.28)$ & $-0.278(0.58)$ & $-0.744(0.27)$ \\
EMIGRANT & $-0.113(0.00)$ & $-0.055(0.00)$ & $-0.109(0.00)$ \\
IMMIGRANT & $-0.074(0.02)$ & $-0.034(0.19)$ & $-0.072(0.03)$ \\
(MPXIMMIGRANT)/100 & $0.366(0.05)$ & $0.222(0.13)$ & $0.364(0.06)$ \\
TURNOUT 2007 & & $0.348(0.00)$ & \\
WEST & & & $0.485(0.63)$ \\
NORTH & & & $0.321(0.73)$ \\
CENTRAL & 0.79 & 0.90 & $0.748(0.40)$ \\
R-SQUARE & & & 0.81 \\
\hline N & & &
\end{tabular}

Notes: The dependent variable is the turnout rate in the 2011 parliamentary election. Definitions of independent variables are given in section 2. Estimates are obtained using the ROBUSTREG procedure of the SAS statistical package with METHOD = LTS (least trimmed squares) and FWLS (final weighted least squares) options. The following observations are picked up by the algorithm as outliers: Ağrı, Gümüşhane, Tunceli, Yozgat, Aksaray, and lğdır in the first regression; Ağrı, Amasya, Gümüşhane, Yozgat, Aksaray, and Iğdır in the second regression; Ağrı, Gümüşhane, Tunceli, Yozgat, Aksaray, and lğdır in the third regression. The numbers in parantheses next to the parameter estimates are the probabilities relevant to the chi-square test of whether the associated coefficient is equal to zero.

We obtained a positive coefficient for URBAN and a negative one for MP, which can be interpreted as turnout being less in urban areas compared to rural ones but the difference being smaller in the case of a typical district or provincial centers as opposed to metropolitan centers. The negative effects of population size and ballot complexity on the turnout is also captured in this result. An increase in the number of members of parliament from a constituency lowers it by about 0.35 points, and each percentage increase in the proportion of the population residing in provincial and district capitals raises it by 0.05 points. The inverse relationship between population size and voter turnout is well established in other studies as well. Geys (2006) notes that one out of three studies use population as a determinant of turnout, and about two-thirds of them find its effect to be negative. Some studies since Geys' survey, for instance Boulding and Brown (2013) on Brazil and Bolivia, Engstrom (2012) on the U.S., and Remmer (2010) on Costa Rica, reach a similar conclusion as well.

Taken at face value, our turnout equation suggests that as the effective number of parties (PARTIES) increase by one, the turnout rate drops by $0.70-0.77$ points. For provinces in which a dominant party captures all seats (NOCOMPETITION $=1)$, a 0.68 point drop in turnout is predicted. However, we cannot reject with confidence these effects being zero. Very small variation in the two variables mentioned does not allow us to measure these effects with precision (Table 1). Still, the direction of the effect hinted by the estimated coefficient of NOCOMPETITION is in agreement with the findings on other countries. Geys (2006) mentions that more than half of the studies include in their turnout equations some measure of electoral competition, and more than 
two-thirds of those find that the stronger the competition, the higher is the turnout. More recent papers by De Paola and Scoppa (2014) on Italy, Engstrom (2012) on the U.S. and Siaroff and Wesley (2011) on Canada reach the same conclusion. On the other hand, Geys notes that only few studies consider effective number of parties as a determinant of turnout, and there is no consensus concerning the sign of this variable's coefficient. Conflicting results are obtained in this regard in more recent studies as well. Boulding and Brown (2013), studying Brazil and Bolivia, and Rowe (2013), examining Spain, find the number of parties to influence turnout positively at the district level in the case of proportional election systems, but Grofman (2011), examining Switzerland and Spain, under similar circumstances, concludes that an increase in the number of parties do not necessarily increase turnout and may even decrease it.

Migration affects turnout adversely both in sending and receiving provinces. A one percentage increase in the ratio of emigrants in the population born in a province reduces turnout by 0.11 points, while a one percentage increase in the proportion of immigrants in a province reduces it by 0.07 . However, as the number of parliament members being elected from a constituency increases, the latter figure is reduced at the rate of about 0.004 per parliament member. Stating it in another way, as the proportion of migrants in the electorate rises, the negative effect of the population size (or MP) on turnout decreases at the rate of about 0.004 per percentage of migrants in the population. This turns the negative impact of migration to positive in electoral districts of Istanbul for example, which have large parliamentary delegations and large concentrations of migrants. The impact is reduced considerably in the electoral districts of Ankara and Izmir, which have sizable populations, more than half of which are migrants.

As we mentioned in the previous section, adverse effects of population mobility on turnout is well established. Geys (2006) reports that about a third of the studies on turnout considered some measure of population mobility as a determinant of turnout, and three-fourths of those obtained a positive coefficient estimate for this variable. Maxwell (2010) finds that non-European origin migrants in France are more likely than natives to have lower turnout rates. Similarly, Siaroff and Wesley (2011) report that Canadian provinces with lower rates of in-migration tend to feature higher rates of voter turnout. Cebula and Toma (2006) find that the voter participation rate in a state in America is negatively impacted by the proportion of the state's population that is Hispanic.

There is at least one study, Shertzer (2013), which finds, like us, that migrants have a greater incentive to participate in elections in areas where their concentrations are high. She finds that immigrants in the U.S. are more likely to become politically mobilized as their ethnic group's share of the local electorate grows relatively larger, peaking at about one fifth of the electorate.

There are very few studies on the impact of migration on those who are left behind in the sending communities. One notable study on this topic is Goodman and Hiskey (2008), which find that emigration reduces electoral participation in Mexico. Our finding provides strong support from the Turkish case for the conclusion reached by that study.

The regressions given in the second columns of Tables 2 and 3 include the turnout rate in 2007. Inclusion of a lagged turnout rate reduces coefficients of all other variables in the equation as it takes part of their explanatory power. However, all coefficients retain their signs, and about half of them retain their statistical significance as well, which implies that they contain additional information that cannot be represented by the lagged 
turnout rate alone. From the increase in the $\mathrm{R}^{2}$ and the high level of significance of its parameter, we can see however that the lagged turnout variable represents other factors as well, such as the act of voting being habit-forming.

The regressions with the regional dummy variables are presented in the last columns of Tables 2 and 3. WEST, NORTH and CENTRAL enter the equation, and EAST is left out as the base. The estimated coefficients of the dummy variables are all small and statistically insignificant, indicating that the variables in the model capture regional differences adequately.

\section{Summary and conclusions}

Internal migration has an adverse effect on political participation both at the origins and destinations of migrants. However, at destinations with large populations (thus large parliamentary delegations) and concentrations of immigrants, the opportunity afforded to immigrants from various regions to elect to parliament one of their own reduces this negative impact considerably, and even turns it to positive in some electoral districts.

The relationship between turnout and education is inverse U-shaped, with a flat top. Behavioral differences among various generations cause the age-turnout relationship to be U-shaped. A large population and large number parliament members elected from a constituency depress the turnout rate. There is a hint in the data that participation by a large number of parties and the existence of a dominant party also impact turnout adversely, but this cannot be stated with confidence.

Most of the results above are similar to what was found in other countries. However, a few of our findings should be considered novel. That emigration has a negative impact on turnout is reported only in one other study. Likewise, even though their participation is lower than that of natives, that immigrants have a greater incentive to participate in elections in areas where their concentrations are high is a result not obtained in too many studies. Our finding that turnout may decline with college education is an important one as well, as it can explain the Brody's (1978) puzzle (why, despite rising education levels, political participation fails to increase). To the best of our knowledge, this explanation was not suggested elsewhere. That electoral participation declined in the post baby-boomer generations in many North American and European countries is well known, but here we were able to show for the first time that this was the case in Turkey as well. We further found that this decline has reversed in Turkey in the generation born after 1980, which entered the electorate with the 2002 election. This explains, at least partially, why the turnout rate in Turkey does not exhibit a declining trend as in Western countries where the political participation of the millennial (Y) generation is especially low. In Turkey this cohort not only turns out even more than the baby boomers, its proportion in the population is much larger than their Western counterparts'.

For our conclusions to gain more credibility, it is necessary to duplicate them with data on elections held at other times and on other types of elections. Perhaps analyses of panel data involving various elections (for members of parliament, for the president, and for local administration officials) would produce more informative and convincing results. It is not available now, but if and when data on proportions of second and third generation migrants in the population, and data on the time elapsed since migration become available, then it will be possible to measure how long the effects of migration last 
as well. We found that a few provinces (Ağrl, Gümüşhane, Tunceli, Yozgat, Aksaray, and Iğdır) differ from the general pattern observed in the rest of the country. Investigating reasons behind such deviations may yield new insights.

\section{Endnotes}

${ }^{1}$ Although place of birth data is available for five year intervals during 1950-2000, it is not for later years. Instead, place of birth registry has been reported since 2008, which is essentially the same as the place of birth. Thus, for the year 2011, we use the former as a near perfect substitute of the latter.

${ }^{2}$ See, for example, Delwit (2013), Bhatti and Hansen (2012), Engstrom (2012), Siaroff and Wesley (2011), Gallego (2009), Heath (2007), Wass (2007), Nakhaie (2006), and Blais et al. (2004).

${ }^{3}$ Since 2008 , the electoral registers in Turkey are prepared and updated regularly by the state which does not require voluntary registration. This is accomplished by matching of two databases through the identification numbers each citizen is assigned. One of the databases, known as "Merkezi Nüfus İdare Sistemi" (the Central Population Registration System) or with its Turkish acronym MERNIS, contains information such as births, deaths, marriages, divorces, and adoptions. The other one, known as "Adrese Dayalı Nüfus Kayit Sistemi” (the Address Based Population Registration System) or with its Turkish acronym, ADNKS, covers addresses of all citizens. For more details about the databases mentioned and how they are matched, the reader is referred to Taştı (2009).

${ }^{4}$ Ideally, the age group 18-29 should be used, as the voting age is 18 . However because Turkstat reports age distribution at 5 year intervals, it is not possible to measure the age group of interest precisely. We are presuming that the 20-29 age group would be a good proxy for the 18-29 age group.

${ }^{5}$ In Turkey, each province, with the exception of the three most populous ones, is considered a constituency. All, except one, elect multiple members to the parliament based on its share in the country's population. Members of parliament are awarded to political parties according to the D'Hondt proportional election system. However, votes of parties which receive less than 10 percent of the vote nationwide are ignored. Istanbul is divided in to three constituencies with 30, 27, and 28 members of parliament, Ankara into two with 16 and 15 members of parliament, and Izmir into two with 13 members of parliament each. We approximated MP to be 28.3 for Istanbul, 15.5 for Ankara and 13 for Izmir.

${ }^{6}$ This is the index suggested by Laakso and Taagepera (1979) for measuring the effective number of parties. However, in computing the index for Turkey, we included only vote shares of the parties which either exceeded the 10 percent nationwide threshold or were able to bypass it by fielding independent candidates. In computing the party vote shares, we ignore the shares of parties not included in the index, as is done by the election system.

${ }^{7} 14$ of the 81 provinces fall under this category. These include six of the 18 provinces with three members of parliament, seven of the 15 provinces with two members of parliament, and the only province with one parliament member.

${ }^{8}$ In many studies, the difference in the vote shares of the two top parties is used as the measure of competitiveness of the election, but that makes sense only in the case of single-member districts. 
${ }^{9}$ Turksat provide 12-way and 26-way partitions of the country. However, using that many dummy variables would exhaust the degrees of freedom and cause multicolinearity. Consequently, we have decided to group them into four regions. A similar approach is used by Akarca and Başlevent (2010) for example, who group Turkstat regions into three.

${ }^{10}$ They also show that the effect of education on voting preference is not working through migration.

\section{Competing interests}

The IZA Journal of Migration is committed to the IZA Guiding Principles of Research Integrity. The authors declare that they have observed these principles.

\section{Acknowledgements}

Earlier versions of this paper were presented at the 11th IZA Annual Migration Meeting (AM $\left.{ }^{2}\right)$ held in Bonn, Germany, May 30 - June 1, 2014, at the Turkish Migration Conference held at Regent's University, London, UK, May 30 - June 1, 2014, and at the $44^{\text {th }}$ Annual Meeting of the Illinois Economic Association held in Chicago, Illinois, USA, October 17-18, 2014. We have benefited greatly from the comments we have received from the audiences and discussants at these gatherings. We would like to thank the anonymous reviewer of the IZA Journal of Migration for his/her valuable suggestions which enhanced the quality of this article.

Responsible editor: Amelie F Constant.

\section{Author details}

${ }^{1}$ Department of Economics (mc 144), University of Illinois at Chicago, 601 S. Morgan Street, Chicago, Illinois 60607, USA. ${ }^{2}$ Department of Economics, Middle East Technical University, Ankara 06531, Turkey. ${ }^{3}$ Institute for Study of Labor (IZA), P.O. Box 7240, Bonn D-53072, Germany. ${ }^{4}$ Economic Research Forum (ERF), Cairo, Egypt.

Received: 9 June 2014 Accepted: 2 December 2014

Published online: 23 January 2015

\section{References}

Akarca AT, Başlevent C (2010) The region-of-origin effect on voting behavior: the case of Turkey's internal migrants. Iktisat İsletme ve Finans 25(297):9-36

Akarca AT, Tansel A (2007) Social and economic determinants of Turkish voter choice in the 1995 parliamentary election. Electoral Studies 26:633-647

Başlevent C (2013) The impact of urbanization on political outcomes in Turkey. Economic Research Forum (ERF) Working Paper No. 799. Economic Research Forum (ERF), Cairo, Egypt

Berinsky AJ, Lenz GS (2011) Education and Political Participation: Exploring the Causal Link. Political Behavior 33:357-373

Bhatti Y, Hansen KM (2012) The effect of generation and age on turnout to the European Parliament - How turnout will continue to decline in the future. Electoral Studies 31:262-272

Blais A, Gidengil E, Nevitte N, Nadeau R (2004) Where does turnout decline come from? European Journal of Political Research 43:221-236

Boulding C, Brown DS (2013) Do political parties matter for turnout? Number of parties, electoral rules and local elections in Brazil and Bolivia. Party Politics: published online: http://ppq.sagepub.com.proxy.cc.uic.edu/content/ early/2013/02/28/1354068813475496.full.pdf+html

Brody R (1978) The puzzle of political participation in America. In: King A (ed) The new American political system. American Enterprise Institute, Washington, DC

Cebula RJ, Toma M (2006) Determinants of geographic differentials in the voter participation rate. Atlantic Economic Journal 34:33-40

Cesur R, Mocan NH (2013) Does secular education impact religiosity, electoral participation and the propensity to vote for Islamic parties? Evidence from an education reform in a Muslim country. Working Paper No. 19769. National Bureau of Economic Research (NBER), Cambridge, MA, USA

Çulhaoğlu B (2007) Electoral participation in Turkish national and local elections. In: Unpublished M.A. thesis. Sabancı University, Istanbul, Turkey (available online: http://research.sabanciuniv.edu/8490/)

De Paola M, Scoppa V (2014) The impact of closeness on electoral participation exploiting the Italian double ballot system. Public Choice 160:467-479

Delwit P (2013) The end of voters in Europe? Electoral turnout in Europe since WWII. Open Journal of Political Science 3:44-52

Engstrom EJ (2012) The Rise and decline of turnout in congressional elections: Electoral institutions, competition, and strategic mobilization. American Journal of Political Science 56:373-386

Gallego A (2009) Where else does turnout decline come from? Education, age, generation and period effects in three European countries. Scandinavian Political Studies 32:23-44

Geys B (2006) Explaining voter turnout: a review of aggregate-level research. Electoral Studies 25:637-663

Goodman GL, Hiskey JT (2008) Exit without leaving: political disengagement in high migration municipalities in Mexico. Comparative Politics 40:169-188

Grofman B (2011) Turnout and the (effective) number of parties at the national and district levels: A puzzle-solving approach. Party Politics 17:93-117

Heath O (2007) Explaining turnout decline in Britain, 1964-2005: party identification and the political context. Political Behavior 29:493-516

Huber PJ (1973) Robust Regression: Asymptotics, Conjectures, and Monte Carlo. Annals of Statistics 1:799-821 
Laakso M, Taagepera R (1979) "Effective" number of parties: a measure with application to West Europe. Comparative Political Studies 12:3-27

Maxwell R (2010) Political participation in France among non-European-origin migrants: Segregation or integration? Journal of Ethnic and Migration Studies 36:425-443

Nakhaie MR (2006) Electoral participation in municipal, provincial and federal elections in Canada. Canadian Journal of Political Science 39:363-390

Pikkov DL (2011) The practice of voting: Immigrant turnout, the persistence of origin effects, and the nature, formation and transmission of political habit. In: Ph.D. thesis. University of Toronto, Toronto, Canada (available online: https://tspace.library.utoronto.ca/bitstream/1807/31900/1/Pikkov_Deanna_L_201108_PhD_thesis.pdf

Remmer KL (2010) Political scale and electoral turnout: Evidence from the less industrialized world. Comparative Political Studies 43:275-303

Rousseeuw PJ (1984) Least median of squares regression. Journal of the American Statistical Association 79:871-880

Rousseeuw PJ, Van Driessen K (2000) An algorithm for positive-breakdown regression based on concentration steps. In: Gaul W, Opitz O, Schader M (ed) Data Analysis: Scientific Modeling and Practical Application. Springer-Verlag, New York, pp 335-346

Rowe KT (2013) Making voice count: Economic voting and the number of parties. Party Politics: published online: http://ppq.sagepub.com.proxy.cc.uic.edu/content/early/2013/12/02/1354068813509516.full.pdf+html

Shertzer A (2013) Working Paper No. 18827. National Bureau of Economic Research (NBER), Cambridge, MA, USA

Siaroff A, Wesley JJ (2011) Explaining comparative voter turnout in the Canadian provinces since 1965: The importance of context. Paper for presented at the Annual Meeting of the American Political Science Association, Seattle, Washington. September 3, 2011

Smets K, Van Ham C (2013) The embarrassment of riches? A meta-analysis of individual-level research on voter turnout. Electoral Studies 32:344-359

Taştı E (2009) Address based population registration system: 2007 population census in Turkey. Received on: 01.06.2012 from: http://unstats.un.org/unsd/censuskb20/KnowledgebaseArticle10663.aspx

Tuncer E (2007) 22 Temmuz 2007 milletvekili genel seçimleri: sayısal ve siyasal değerlendirme [22 July 2007 Elections for members of parliament: a quantitative and political evaluation]. TESAV (in Turkish), Ankara, Turkey

Tuncer E (2011) 12 Haziran 2011 milletvekili genel seçimleri: sayısal ve siyasal değerlendirme [12 June 2011 elections for members of parliament: a quantitative and political evaluation]. TESAV (in Turkish), Ankara, Turkey

Wass H (2007) The effects of age, generation and period on turnout in Finland 1975-2003. Electoral Studies 26:648-659

Zaman A, Rousseeuw PJ, Orhan M (2001) Econometric applications of high-breakdown robust regression techniques. Econometrics Letters 71:1-8

Submit your manuscript to a SpringerOpen ${ }^{\circ}$ journal and benefit from:

- Convenient online submission

- Rigorous peer review

- Immediate publication on acceptance

- Open access: articles freely available online

- High visibility within the field

- Retaining the copyright to your article

Submit your next manuscript at $>$ springeropen.com 